\title{
Enhanced antifungal activity of bovine lactoferrin-producing probiotic Lactobacillus casei in the murine model of vulvovaginal candidiasis
}

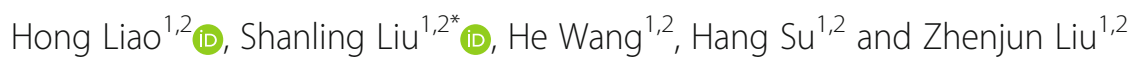

\begin{abstract}
Background: Vulvovaginal candidiasis (WC) is a common vaginitis caused by Candida species,a frequently recurring condition. Fungal azole-resistant strains with azole-resistance have developed for long and wide explosion to the first-line antifungal azole agent. Bovine lactoferrin (BLF) is a protein from transferrin family secreted by the bovine mammary tissue. Its various biological functions are well known, especially the pronounced antifungal activity.

Results: In the current study, we constructed a Lactobacillus casei strain (L.casei/pPG612.1-BLF), which secreted BLF encoded by a mature secretion vector plasmid PPG612.1, and evaluated its antifungal activity in vitro and in vivo. In a two-layer agar plate in vitro assay, the number of C. albicans CFUs decreased and the average colony size shrunk upon exposure to L. casei/pPG612.1-BLF. In a murine WC model, the infection burden of mice intra-vaginally pre-inoculated with L. casei/pPG612.1-BLF was lower than in control groups. Furthermore, the infection burden in mice with WC was reduced when the animals were continually given L. casei/pPG612.1-BLF as a topical treatment for 5 days.

Conclusion: Combined, these results suggested that the L. casei/pPG612.1-BLF strain is a promising preventative and therapeutic anti-WC agent, highlighting the possibility of employing the probiotic L. casei as a vehicle for biotherapy in the female genital tract and exploiting the natural antibiotic antimicrobial peptides for other applications.
\end{abstract}

Keywords: Vulvovaginal candidiasis, Bovine lactoferrin, Antimicrobial peptides, Lactobacillus casei, Antifungal activity, Heterologous expression

\section{Background}

Vulvovaginal candidiasis (VVC) is the second most common infection disease in female genitourinary tract after bacterial vaginosis. It can affect up to $75 \%$ of women of childbearing age [1]. Symptoms, including burning pain, intense pruritus and abnormal "cheese-like" or watery vaginal discharge, are typical $[2,3]$. Candida. Albicans (C. albicans), identified as the most common pathogen in VVC, is commensal fungi colonizing in female genitourinary tracts [4]. Certain risk factors, e.g., oral contraceptive

\footnotetext{
* Correspondence: sunny630@126.com

'Department of Obstetric \& Gynecologic, West China Second University Hospital, Sichuan University, NO. 17.3rd Section, Renmin South Road, Chengdu, Sichuan 610041, China

${ }^{2}$ Key Laboratory of Birth Defects and Related Diseases of Women and

Children (Sichuan University), Ministry of Education, Chengdu, China
}

usage, pregnancy, uncontrolled diabetes mellitus, and longterm broad spectrum antibiotic treatment, may cause it to become pathogenic [5-7]. The virulence factors were considered as the morphogenetic transition, the expression of adhesins and invasins, the formation of biofilms, phenotypic switching and the secretion of hydrolytic enzymes when invading the host [8].

Clinically, azoles are the first-line agents both in topical and oral VVC treatment [9, 10]; however, fungal strains exhibiting azole resistance, especially fluconazole resistance, have emerged $[11,12]$. Research on new therapeutic agents, e.g., azole derivatives and amphotericin B, nikkomycin Z, and antimicrobial peptides (AMPs), shows their promising fungicidal activity; otherwise, preventative approaches, e.g.,

(C) The Author(s). 2019 Open Access This article is distributed under the terms of the Creative Commons Attribution 4.0 International License (http://creativecommons.org/licenses/by/4.0/), which permits unrestricted use, distribution, and reproduction in any medium, provided you give appropriate credit to the original author(s) and the source, provide a link to the Creative Commons license, and indicate if changes were made. The Creative Commons Public Domain Dedication waiver (http://creativecommons.org/publicdomain/zero/1.0/) applies to the data made available in this article, unless otherwise stated. 
vaccines interfering with immunological sensitization, are also feasible [13-15].

AMPs are widely recognized as a group of cationic peptides with antimicrobial and immuno-modulating properties; they are produced by a variety of species $[16,17]$. As key components of the innate immunity, they function as the first barrier defending the host against a wide array of pathogens, from bacteria and fungi to protozoa [18]. Bovine lactoferrin (BLF), a member of the transferrin family of proteins with various biological functions, is abundant in bovine milk glycoproteins as well as in other secreted fluids [19]. It has attracted a lot of attention because of its pronounced bactericidal and fungicidal activity against a wide range of microorganisms at the mucosal surfaces $[20,21]$. As a natural AMP agent with little toxicity to the host cells, BLF is a subject of research for its potential use in treatment and prevention of fungal infections [22, 23].

Lactobacillus species, Gram-positive bacteria, are dominant members of the natural microbiota of the vaginal and gastrointestinal tract, maintaining the vaginal microenvironment to prevent pathogen invasion [24, 25]. Since they are regarded as safe, Lactobacillus strains are widely employed by the fermented food and beverage industry, and used as vaccine delivery systems to activate the mucosal immunity in animal models [26, 27]. Some studies demonstrated the effectiveness of topical or oral administration of certain Lactobacillus strains as probiotics in preventing the recurrence of VVC, but consistent evidence of their effectiveness still lacking $[28,29]$. Further, no investigations concerning the utilization of AMP-producing Lactobacillus strains in the vaginal tract have been reported. In the current study, we constructed a BLF-producing system based on the plasmid pPG612.1 and Lactobacillus casei ATCC 393, and evaluated its preventative and therapeutic activity in the murine model of VVC.

\section{Results}

Construction of a $L$. casei strain secreting BLF

The L. casei/pPG612.1-BLF harboring the plasmid pPG612.1-BLF was grown on MRS agar or broth supplemented with $10 \mu \mathrm{g} / \mathrm{mL} \mathrm{Cm}$. Amplification of the BamHI and XhoI sites of the plasmid pPG612.1-BLF isolated from the $L$. casei/pPG612.1-BLF strain resulted in 500-bp product; sequencing of the PCR products verified the successful insertion of the BLF coding sequence in plasmid pPG612.1(data not shown). Following protein precipitation, electrophoresis, and western blotting, Immunoreactive bands corresponding to BLF (78 kD) were observed between the $72-\mathrm{kD}$ and $95-\mathrm{kD}$ size markers on film, both in the supernatant and pellet of the L. casei/ pPG612.1-BLF overnight culture, but not in untransformed L. casei cells (Fig. 1).

\section{Fungicidal effects of $L$. casei/pPG612.1-BLF against C.albicans in vitro}

We developed a two-layer agar dish assay, which allowed C. albicans to be directly exposed to the secretions of the $L$. casei/pPG612.1-BLF; i.e., $L$. casei cells were grown anaerobically in the bottom MRS layer, while $C$. albicans cells were grown on the surface of the top SDA layer. The quantity and average size of $C$. albicans colonies were analyzed to evaluate the antifungal effect of BLF produced by L. casei/pPG612.1-BLF. After a 24-h incubation, $C$. albicans colonies formed in the absence of $L$. casei were readily discernible, but they were smaller after incubation in the presence of $L$. casei/pPG612.1-BLF and L. casei (Fig. 2a). After $48 \mathrm{~h}$ of incubation, the colonies in each group were counted, and the colony diameter was measured using a vernier caliper. As observed, the CFU number of $C$. albicans grown in the presence of $L$. casei/pPG612.1-BLF $(53.67 \pm 1.53)$ was lower than of cells grown with $L$. casei/ pPG612.1 $(86.00 \pm 2.64)$ or L. casei $(87.67 \pm 1.53)(P<0.01)$; no difference in CFU numbers was apparent between the two latter groups (Fig. 2b). Additionally, the CFU numbers of C. albicans grown in the absence of L. casei $(95.00 \pm 3.61)$ and without MRS $(98.33 \pm 3.51)$ were higher than those of cells grown in the presence of L. casei/pPG612.1 or L. casei.

Regarding the average colony size in each group, the fungal colonies grown in the presence of $L$. casei/pPG612.1-BLF $(0.57 \pm 0.18 \mathrm{~mm})$ were smaller than those of cells grown in the presence of $L$. casei/pPG612.1 $(1.23 \pm 0.15 \mathrm{~mm})$ or $L$. casei $(1.18 \pm 0.03 \mathrm{~mm})(P=0.02)$; no difference was apparent between the two latter groups (Fig. 2c). After $36 \mathrm{~h}$ of incubation, C. albicans colonies that grew on the two-layer plates in the absence of $L$. casei $(6.07 \pm 0.21 \mathrm{~mm})$ appeared to be flatter and bigger than those grown on SDA without MRS $(4.23 \pm 0.10 \mathrm{~mm})(P<0.05)$, indicating that MRS medium alone could contribute to the growth of $C$. albicans. Overall, these results suggested that BLF secreted by the $L$. casei/ pPG612.1-BLF strain infiltrated the SDA, interfering with the growth of C. albicans ATCC 10231, as reflected by the colony number and average colony size.

\section{Protective effect of $L$. casei/pPG612.1-BLF in the VVC mouse model}

All animals during the experiment stayed alive before sacrifice. Two days after the inoculation of murine vagina with $20 \mu \mathrm{L}$ of an undiluted PBS suspension of $L$. casei/pPG612.1-BLF (Fig. 3a), the secreted BLF was detected above the epithelial layer using immunohistochemistry (Fig. 3b). To explore the preventative effects of the L. casei/pPG612.1-BLF against VVC in a mouse model, undiluted suspensions of $L$. casei/pPG612.1-BLF, L. casei/pPG612.1, and L. casei were tested, with $20 \mu \mathrm{L}$ of PBS as a blank control. 

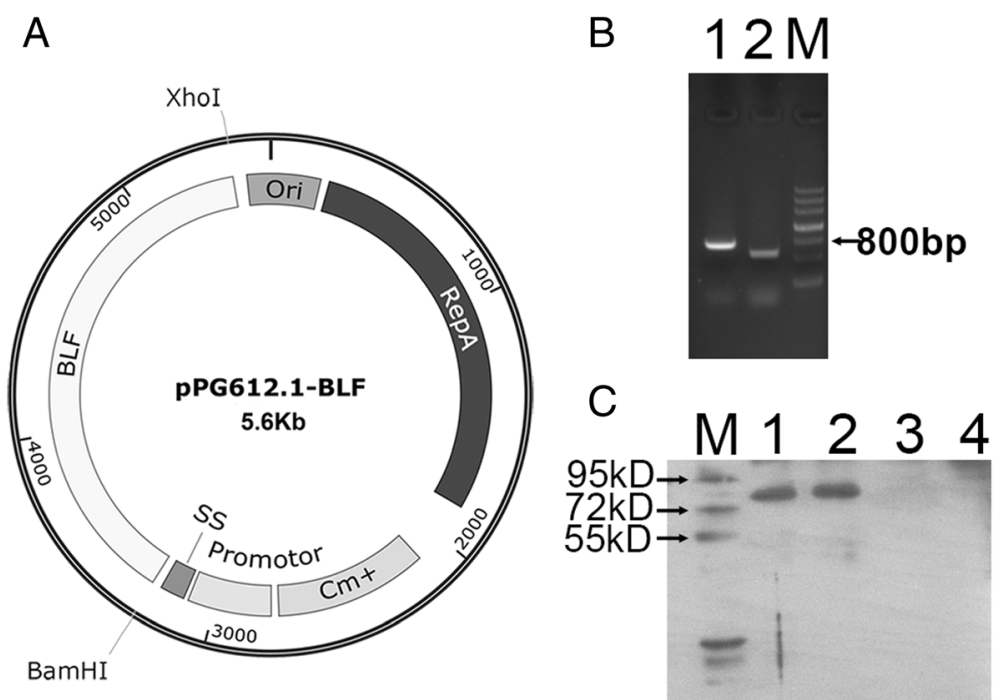

Fig. 1 Construction and expression of the secretion plasmid pPG612.1-BLF in L.casei. a The synthetic BLF gene fragment (2.1 kp) was digested with restriction enzymes BamHI and Xhol, and ligated into the sticky end of the plasmid pPG612.1 which was also digested with the same restriction enzyme, resulting in the plasmid pPG612.1-BLF (5.6kp). b The plasmid pPG612.1-BLF was electroporated into L.casei using a BioRad GenePulser with single electric pulse (voltage, $1.5 \mathrm{kV}$; capacitance, $25 \mu \mathrm{F}$; and resistance, $400 \Omega$.). PCR amplification of the BamHI site and Xhol site of the plasmid pPG612.1-BLF which was extracted from the L.casei/pPG612.1-BLF strain resulted in 500 bp and 800 bp products, respectively. Lane 1, PCR product of Xhol site; Lane 2, PCR product of BamHI site. M, DNA maker. c BLF was detected in the supernatant and pellet of L.casei/pPG612.1-BLF culture by Western blotting, indicating the expression and secretion of BLF by L.casei/pPG612.1-BLF. Lane 1, supernatant of L.casei/pPG612.1-BLF culture; Lane 2, pellet of L.casei/pPG612.1-BLF culture; Lane 3, supernatant of L.casei/pPG612.1 culture; Lane 4, pellet of L.casei/pPG612.1 culture

Following a 7-day inoculation of the murine vagina with different $L$. casei strains, $20 \mu \mathrm{L}$ of a $C$. albicans suspension in PBS $\left(10^{8} \mathrm{CFU} / \mathrm{mL}\right)$ was used to inoculate the mouse vagina on day 8 (Fig. $4 \mathrm{a}$ ). The vaginal lavage of each mouse was collected on day 10 , and C. albicans CFUs were determined in each sample to analyze the infection burdens. The infection burden in mice receiving L. casei/pPG612.1-BLF $\left(4.404 \pm 0.040 \log _{10} \mathrm{CFU} / \mathrm{mL}\right)$ was significantly lower $(P<0.01)$ than in mice receiving $L$. casei/pPG612.1 $\left(4.643 \pm 0.035 \log _{10} \mathrm{CFU} / \mathrm{mL}\right), \quad$ L. casei $\left(4.633 \pm 0.032 \log _{10} \mathrm{CFU} / \mathrm{mL}\right)$, and PBS $(4.585 \pm 0.112$ $\log _{10} \mathrm{CFU} / \mathrm{mL}$ ), indicating that the prophylactic vaginal inoculation with the L. casei/pPG612.1-BLF exerted a protective effect against $C$. albicans (Table 1). However, the fungal infection burden in mice receiving $L$. casei strains that did not produce BLF was the same as in PBS group. Similar to the fungicidal effect observed with the two-layer dish assay in vitro, BLF secreted in the murine vagina by the $L$. casei/pPG612.1-BLF strain was able to prevent the invasion and inhibit the growth of C. albicans in vivo.

C. albicans stimulates the host's immune response during infection, including the activation of immune cells and the production of several types of cytokines. IL-17, mainly produced by the Th17 subset of CD4+ lymphocytes, plays an important role in the mucocutaneous candidiasis, positively correlating with the infection burden, namely, higher IL-17 levels correspond to a more serious infection burden [30-32]. Additionally, IL-23 is essential for Th17 cell expansion and function, which is associated with the production of IL-17 [33]. Therefore, we quantitatively analyzed the IL-17 and IL-23 levels in the vagina lavage samples 2 days after the infection. The IL-17 and IL-23 levels increased after $C$. albicans infection in all mouse groups $(P<0.01)$; however, the IL-17 levels were $19.07 \pm 1.50 \mathrm{pg} / \mathrm{mL}$ in the $L$. casei/ pPG612.1-BLF group. They were distinctly lower $(P=0.01)$ than in the L. casei/pPG612.1 $(25.98 \pm 5.10 \mathrm{pg} / \mathrm{mL})$, L. casei $(25.42 \pm 3.22 \mathrm{pg} / \mathrm{mL})$, and PBS groups $(24.74 \pm 1.87 \mathrm{pg} /$ $\mathrm{mL}$ ), illustrating a milder VVC infection burden in mice that received a prophylactic inoculation with the $L$. casei/ pPG612.1-BLF (Fig. 4b). Similarly, changes in the IL-23 levels were observed; the levels were lower in the $L$. casei/ pPG612.1-BLF group $(11.43 \pm 1.17 \mathrm{pg} / \mathrm{mL})(P=0.035)$ than in the $L$. casei/pPG612.1 $(13.73 \pm 2.67 \mathrm{pg} / \mathrm{mL}), \quad L$. casei $(14.20 \pm 0.92 \mathrm{pg} / \mathrm{mL})$, and PBS groups $(14.56 \pm 1.35 \mathrm{pg} / \mathrm{mL})$ (Fig. 4c). Thus, the observed IL-17 and IL-23 levels reconfirmed the notion that the L. casei/pPG612.1-BLF strain producing BLF in the murine vagina exhibits a protective role against VVC in vivo. A week after the infection, the percentage of $\mathrm{CD}_{4}^{+} \mathrm{T}$ cells in the lumber lymph nodes changed because of the activation of the adaptive immune system by $C$. albicans in the vagina. Thus, less $\mathrm{CD} 4^{+} \mathrm{T}$ cells were observed in the $L$. casei/pPG612.1-BLF group than in the control groups (L. casei/pPG612.1, L. casei, and PBS groups) because less pathogen cells remained in vaginal 
A $12 \mathrm{~h}$
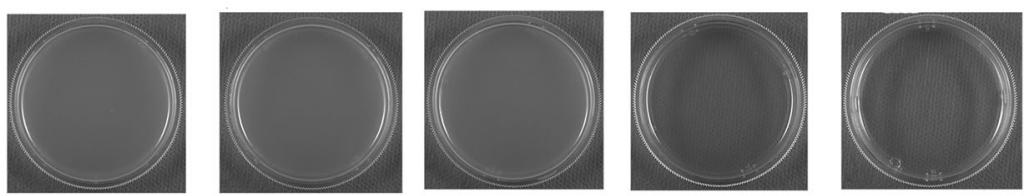

$24 \mathrm{~h}$
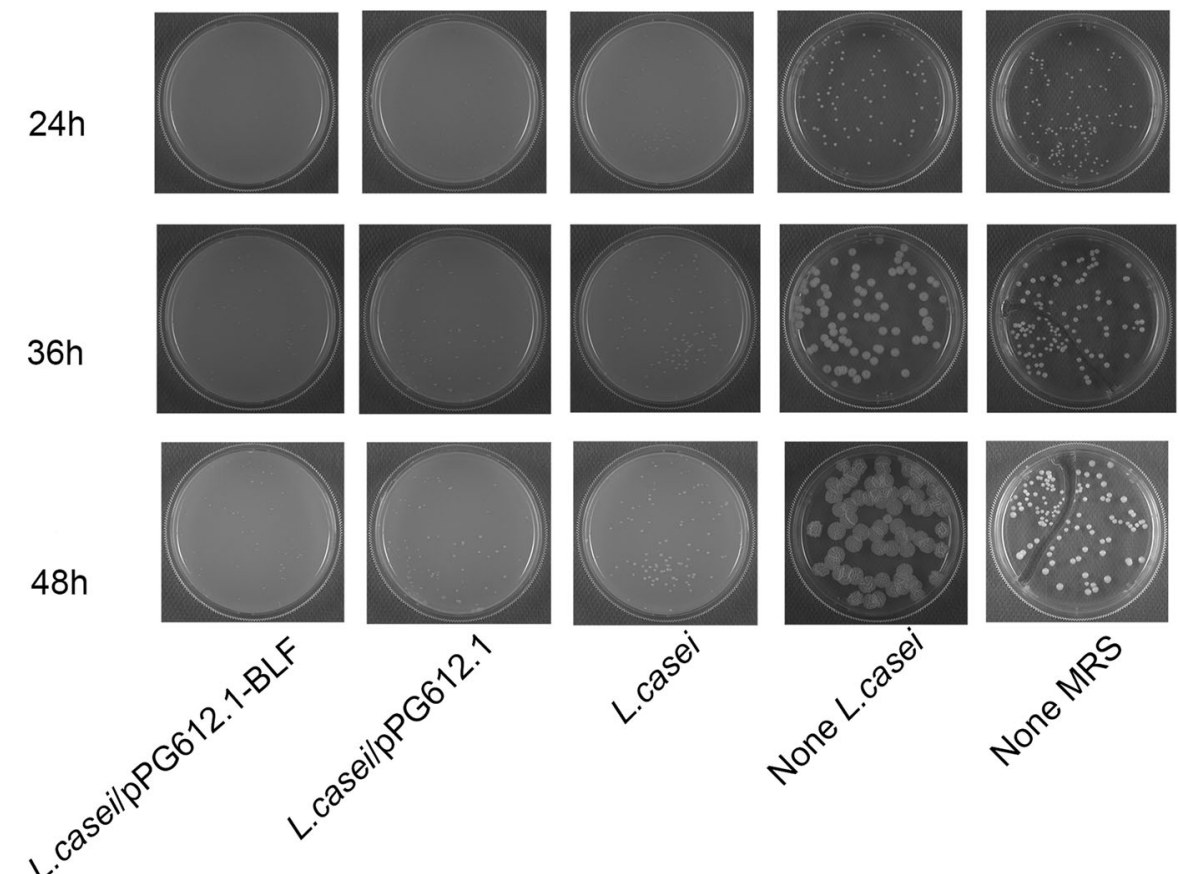<smiles>CC=[C+]1CCCC1</smiles>
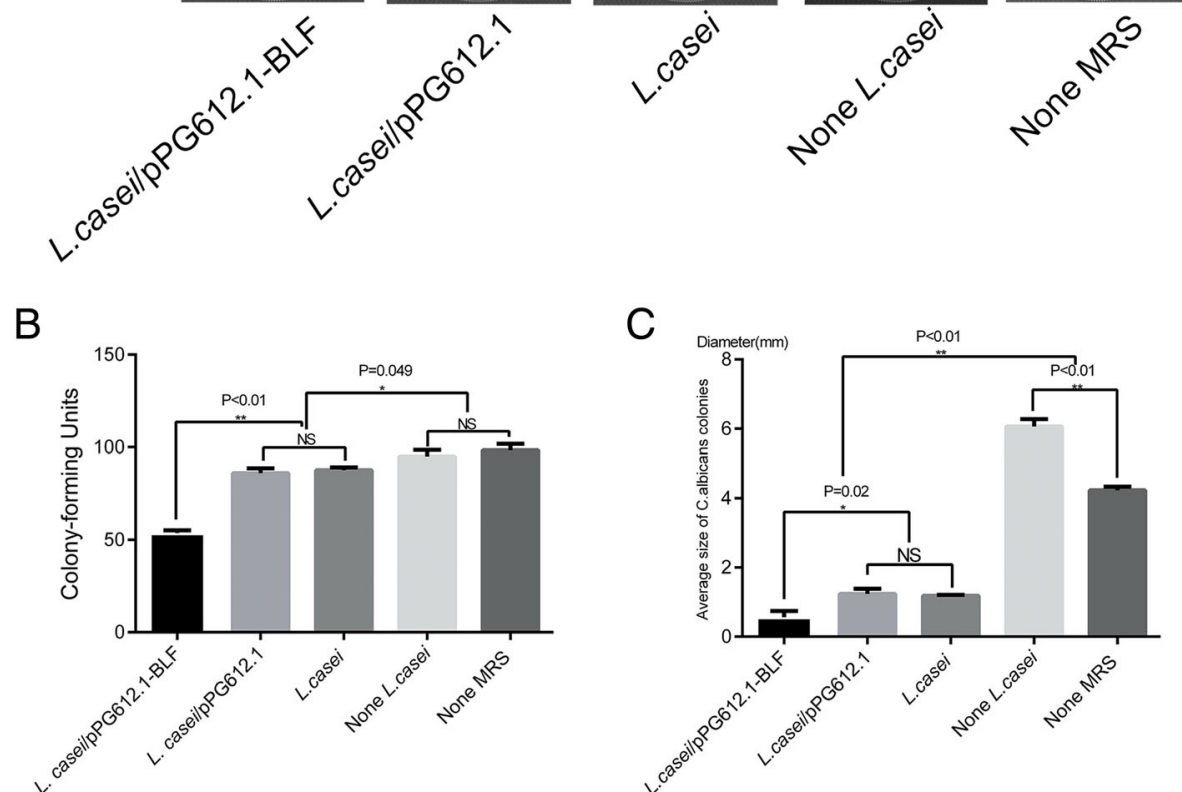

Fig. 2 Antifungal activity of L.casei/pPG612.1-BLF in vitro. a C.albicans and L.casei/pPG612.1-BLF were incubated together on a two-layer agar dish at $37^{\circ} \mathrm{C}$ for $48 \mathrm{~h}$, C.albicans on the top SDA layer and L.casei/pPG612.1-BLF in the bottom MRS layer. Photos were taken every $12 \mathrm{~h}$. b Twenty microliter of L.casei/pPG612.1-BLF (OD600 $\left.=0.6,5 \times 10^{7}-1 \times 10^{8} \mathrm{cell} / \mathrm{s} / \mathrm{mL}\right)$ was added into $200 \mathrm{ml}$ of MRS medium with $1.5 \%$ low melting agarose and mixed gently in the $37^{\circ} \mathrm{C}$ water bath. Before cooling down, $20 \mathrm{ml}$ of the mix was poured onto each culture dish (60 mm diameter) and allowed to solidify. Another $10 \mathrm{ml}$ of SDA with $1.5 \%$ low melting agarose was poured on to the top of the MRS agar, and then allowed to solidify. Following that, $100 \mu \mathrm{L}$ of C.albicans liquid containing about 100 cells was placed on the surface of the two-layer agar dish. Two-layer agar dishes containing L.casei/pPG612.1, L.casei and none L.casei were taken as negative controls, one-layer SDA dishes containing C.albicans alone (None MRS) were taken as blank controls. The CFUs of C.albicans incubated with L.casei/pPG612.1-BLF (53.67 \pm 1.53 CFUs) were fewer than that grown with L.casei/pPG612.1 (86.00 \pm 2.64 CFUs) and L.casei ( $87.67 \pm 1.53$ CFUs) $(P<0.01)$, but there was no difference of CFUs between the latter two groups. Additionally, the CFUs of C.albicans without L.casei (None L.casei, $95.00 \pm 3.61$ CFUs) and without MRS (None MRS, $98.33 \pm 3.51$ CFU) were more than those with L.casei/pPG612.1 or L.casei. (C) The average size of C.albicans CFUs with L.casei/pPG612.1-BLF $(0.57 \pm 0.18 \mathrm{~mm})$ was smaller than that with L.casei/pPG612.1 $(1.23 \pm 0.15 \mathrm{~mm})$ and L.casei $(1.18 \pm 0.03 \mathrm{~mm})(P=0.02)$. C.albicans CFUs on two-layer dishes without L.casei (None L.casei, $6.07 \pm 0.21 \mathrm{~mm}$ ) was flatter and bigger than that grown without MRS dishes (None MRS, $4.23 \pm 0.10 \mathrm{~mm})(P<0.01$ ) 


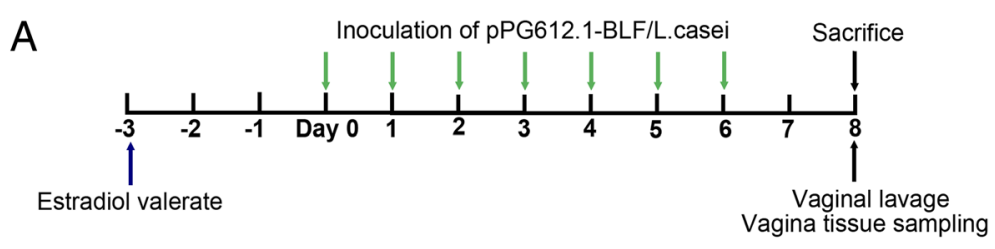

B

L.casei/pPG612.1-BLF
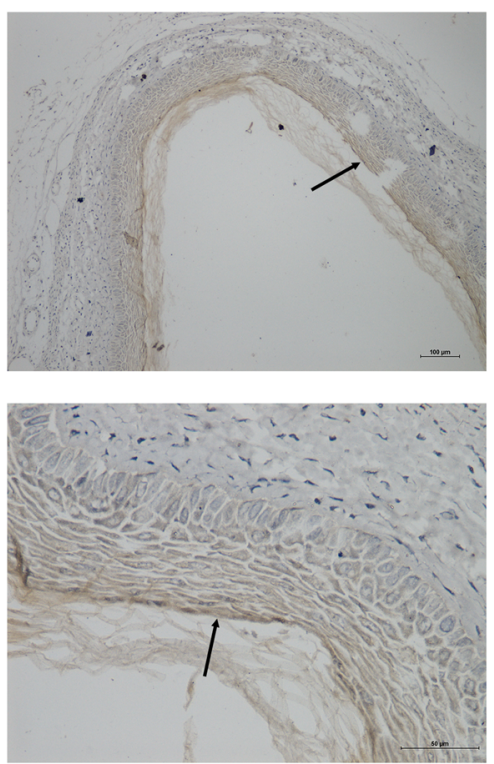

L.caseilpPG612.1
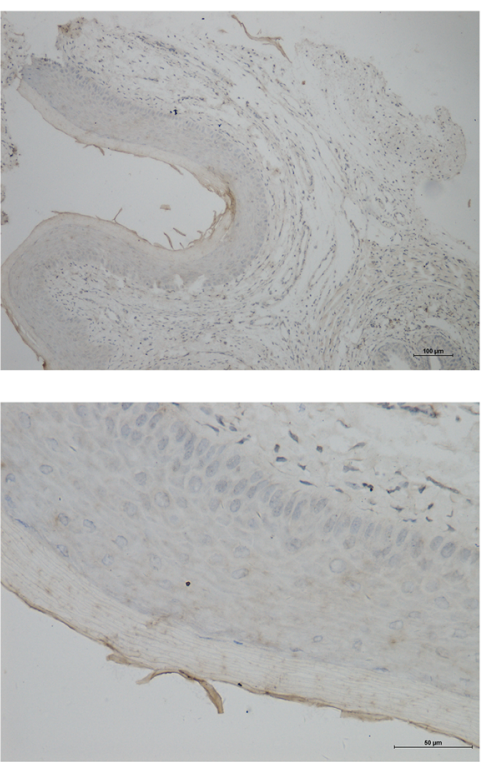

Fig. 3 Colonization of murine vagina by L. casei/pPG612.1-BLF. a Subcutaneous injection of $100 \mu \mathrm{g}$ of estradiol valerate was given to mice 3 days before inoculation. Twenty microliters of undiluted L. casei/pPG612.1-BLF suspension and of the two dilutions were used to inoculate the murine vaginal cavity ( 5 mice per group) with a pipette at the same time of day for seven consecutive days. Mice were sacrificed by cervical dislocation 2 days after the 7th inoculation; each murine vagina was washed gently with $150 \mu \mathrm{L}$ of sterile PBS by repeated aspiration, 10 times. The vaginal tissues were fixed in 4\% paraformaldehyde and embedded in paraffin prior to immunohistochemical analysis with anti-BLF primary antibodies. $\mathbf{b}$ A brown positive band (black arrow) was observed above the vaginal epithelial layer from mice which were inoculated with L. casei/pPG612.1-BLF into the vagina, while it was not detected in the samples from mice receiving inoculation of pPG612.1/L.casei

cavity after being killed by the concentrated BLF secreted by L. casei/pPG612.1-BLF.

\section{Therapeutic effects of L. casei/pPG612.1-BLF in the murine VVC model}

To evaluate the therapeutic effect of the L. casei/ pPG612.1-BLF strain in the murine VVC, $20 \mu \mathrm{L}$ of an $L$. casei/pPG612.1-BLF suspension or other agents were delivered into the murine vagina with a pipette for five consecutive days (Fig. 5a). Overall, the infection burdens in all groups were reduced after a 5-day treatment, which was partly attributed to the natural immune response, but the reductions were more remarkable in groups receiving $L$. casei/pPG612.1-BLF or clotrimazole than in the PBS group. Specifically, the infection burden in the L. casei/pPG612.1-BLF group was $1.710 \pm 0.390$ $\log _{10} \mathrm{CFU} / \mathrm{mL}$; this was lower than in the clotrimazole group $\left(0.492 \pm 0.170 \log _{10} \mathrm{CFU} / \mathrm{mL}\right) \quad(P<0.001)$, but higher than that in the L. casei/pPG612.1 (3.170 \pm $\left.0.252 \log _{10} \mathrm{CFU} / \mathrm{mL}\right)$ and $L$. casei groups $(2.936 \pm 0.259$ $\left.\log _{10} \mathrm{CFU} / \mathrm{mL}\right)(P<0.01)$ (Table 2).

Quantitative analysis of the IL-17 levels in the vaginal lavage revealed that the cytokine levels in all groups were persistently elevated during the treatment after the infection; however, this effect was most apparent in mice receiving $\mathrm{PBS}$ and least apparent in mice treated with $20 \mathrm{mg} / \mathrm{mL}$ clotrimazole. Compared with the L. casei/ pPG612.1 group $(36.42 \pm 2.80 \mathrm{pg} / \mathrm{mL})$ and $L$. casei group $(34.71 \pm 2.18 \mathrm{pg} / \mathrm{mL})$, less IL-17 $(\mathrm{P}<0.01)$ was detected in the $L$. casei/pPG612.1-BLF group $(29.08 \pm 1.33 \mathrm{pg} / \mathrm{mL})$ after the completion of treatment (Fig. 5b). Regarding the IL-23 levels, they were highest in the PBS group $(12.15 \pm 1.89 \mathrm{pg} / \mathrm{mL})$ and lowest in the clotrimazole group $(8.60 \pm 1.02 \mathrm{pg} / \mathrm{mL})$ after the treatment. Moreover, they were significantly lower $(P=0.026)$ in the $L$. casei/ pPG612.1-BLF group $(9.65 \pm 1.74 \mathrm{pg} / \mathrm{mL})$ than in the $L$. casei/pPG612.1 $(10.46 \pm 0.73 \mathrm{pg} / \mathrm{mL})$ and $L$. casei groups $(10.95 \pm 1.02 \mathrm{pg} / \mathrm{mL})$ (Fig. 5c). 

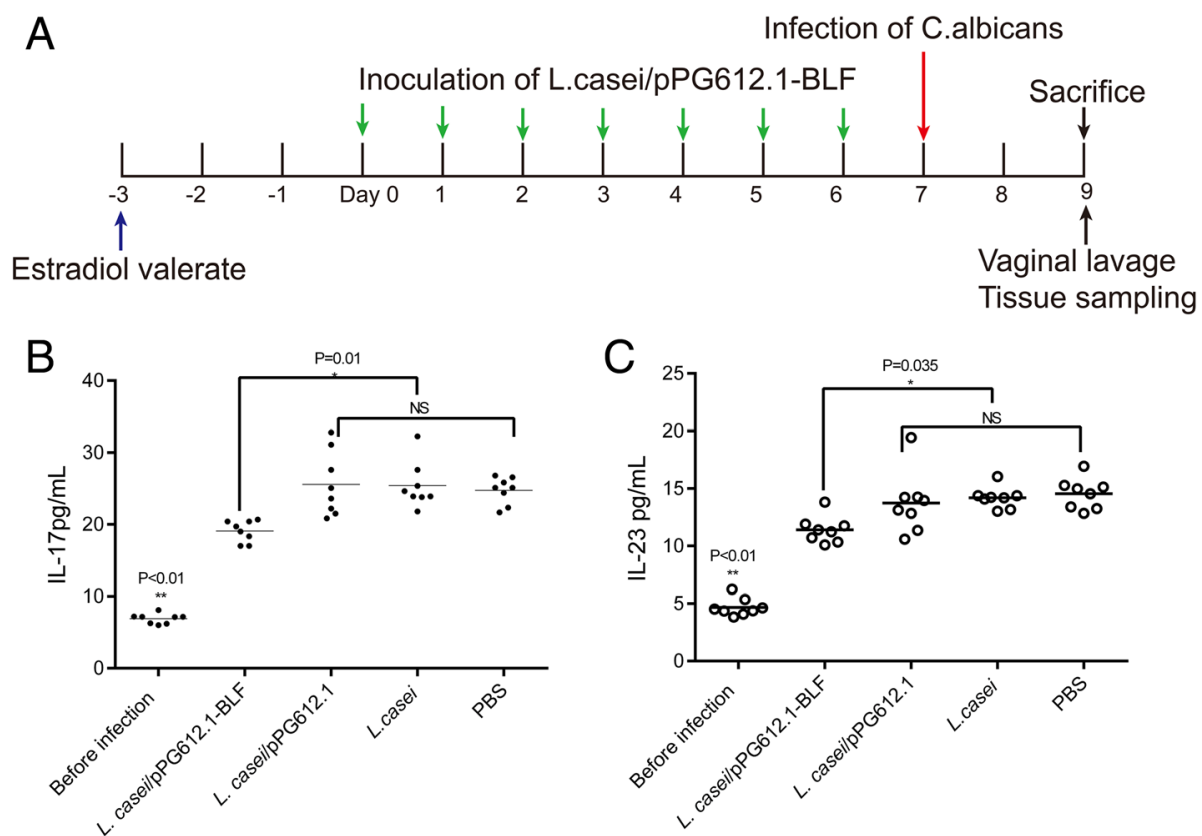

Fig. 4 Protective effect of L. casei/pPG612.1-BLF in the WC mouse model. a Estradiol valerate was given 3 days before inoculation. Following the application of the L. casei/pPG612.1-BLF into the murine vagina, the animals were infected with $20 \mu \mathrm{L}$ of a C. albicans suspension in PBS at $10^{8}$ $\mathrm{CFU} / \mathrm{mL}$ delivered into the vaginal cavity. Two days after the infection, all mice were sacrificed and their vaginas were washed with $150 \mu \mathrm{L}$ sterile PBS prior to being excised and fixed. $\mathbf{b}$ Vaginal lavages were centrifuged and the supernatant was analyzed for the concentration of IL-17 and IL-23 in the lavage before and after infection by ELISA tests according to the manufacturer's recommendations. The concentration of IL-17 and IL-23 had been increased after infection with WC in all mice groups $(P<0.01)$. The concentration of IL-17 was $19.07 \pm 1.50 \mathrm{pg} / \mathrm{mL}$ in L.casei/pPG612.1-BLF group, significantly lower than $(P=0.01)$ those in L.casei/pPG612.1 group $(25.98 \pm 5.10 \mathrm{pg} / \mathrm{mL})$, L.casei group $(25.42 \pm 3.22 \mathrm{pg} / \mathrm{mL})$ and PBS group $(24.74 \pm 1.87 \mathrm{pg} / \mathrm{mL})$. c As for the IL-23, it was lower in L.casei/pPG612.1-BLF group (11.43 $\pm 1.17 \mathrm{pg} / \mathrm{mL})(P=0.035)$, in comparison with that in L.casei/pPG612.1 group (13.73 $\pm 2.67 \mathrm{pg} / \mathrm{mL})$, L.casei group $(14.20 \pm 0.92 \mathrm{pg} / \mathrm{mL})$ and PBS group $(14.56 \pm 1.35 \mathrm{pg} / \mathrm{mL})$

As revealed by the dual-color flow cytometry analysis, the change in the percentage of CD4+ T cells in the vaginal draining lymph nodes between pre-infection and post-infection varied among groups. Overall, the fungus triggered the cell-mediated immunity in the local vaginal tissues and the draining lymph nodes, resulting in increased percentage of CD4+ T cells in the lumbar lymph nodes post-infection. Specifically, in the PBS group, the percentage of $\mathrm{CD} 4+\mathrm{T}$ cells in the murine lumbar lymph nodes was $48.09 \pm 3.53 \%$; it was $46.93 \pm 2.42 \%$ in L. casei group and $45.55 \pm 2.07 \%$ in the $L$. casei/pPG612.1 group, and was higher $(P=0.04)$ than in the $L$. caseil pPG612.1-BLF group $(39.34 \pm 1.34 \%)$ and clotrimazole group $(38.65 \pm 1.94 \%)$. This indicated an effective treatment

Table 1 Infection burden of WC in groups receiving different treatments pior-infection

\begin{tabular}{ll}
\hline Treatment & $\begin{array}{l}\text { Infection burden of WC } \\
\left(\log _{10} \text { CFU) post-inoculation }\right.\end{array}$ \\
\hline PBS & $4.585 \pm 0.112$ \\
L.casei/pPG612.1-BLF & $4.404 \pm 0.040^{*}$ \\
L.casei/pPG612.1 & $4.643 \pm 0.035$ \\
L.casei & $4.633 \pm 0.032$ \\
\hline
\end{tabular}

${ }^{*} P<0.01$ in comparison with PBS, L.casei/pPG612.1-BLF and L.casei groups in the latter two groups, which were able to clear more pathogens, thus reducing the intensity of the immune response in the local vaginal tissues (Fig. 6a).

Vaginal lavage smears from mice with VVC before and after treatment were stained with the Diff-Quik stain. Only few anucleated cornified epithelial cells were observed in samples from healthy untreated mice. Post-infection with fungi (prior treatment), many filamentous pseudohyphae (violet) and cornified squamous epithelial cells (pink) were apparent in each sample. Following a 5-d treatment, in samples from the same mice receiving a vaginal topical treatment with $L$. casei/pPG612.1-BLF or clotrimazole, fewer epithelial cells were apparent than that prior the treatment, with several neutrophils (blue) and no filamentous pseudohyphae (Fig. 6b). In contrast, in samples from mice receiving L. casei/pPG612.1, L. casei, or PBS, copious numbers of epithelial cells were observed with filamentous pseudohyphae (PBS group) or without filamentous pseudohyphae (L. casei/pPG612.1 and L. casei groups).

To observe the fungi in the vagina, the tissues were fixed and processed for PAS staining. Unlike in the healthy untreated mice, with no $C$. albicans visible in the vaginal cavity after H\&E/PAS staining, the vaginal cavity from infected animals was filled with large numbers of filamentous 


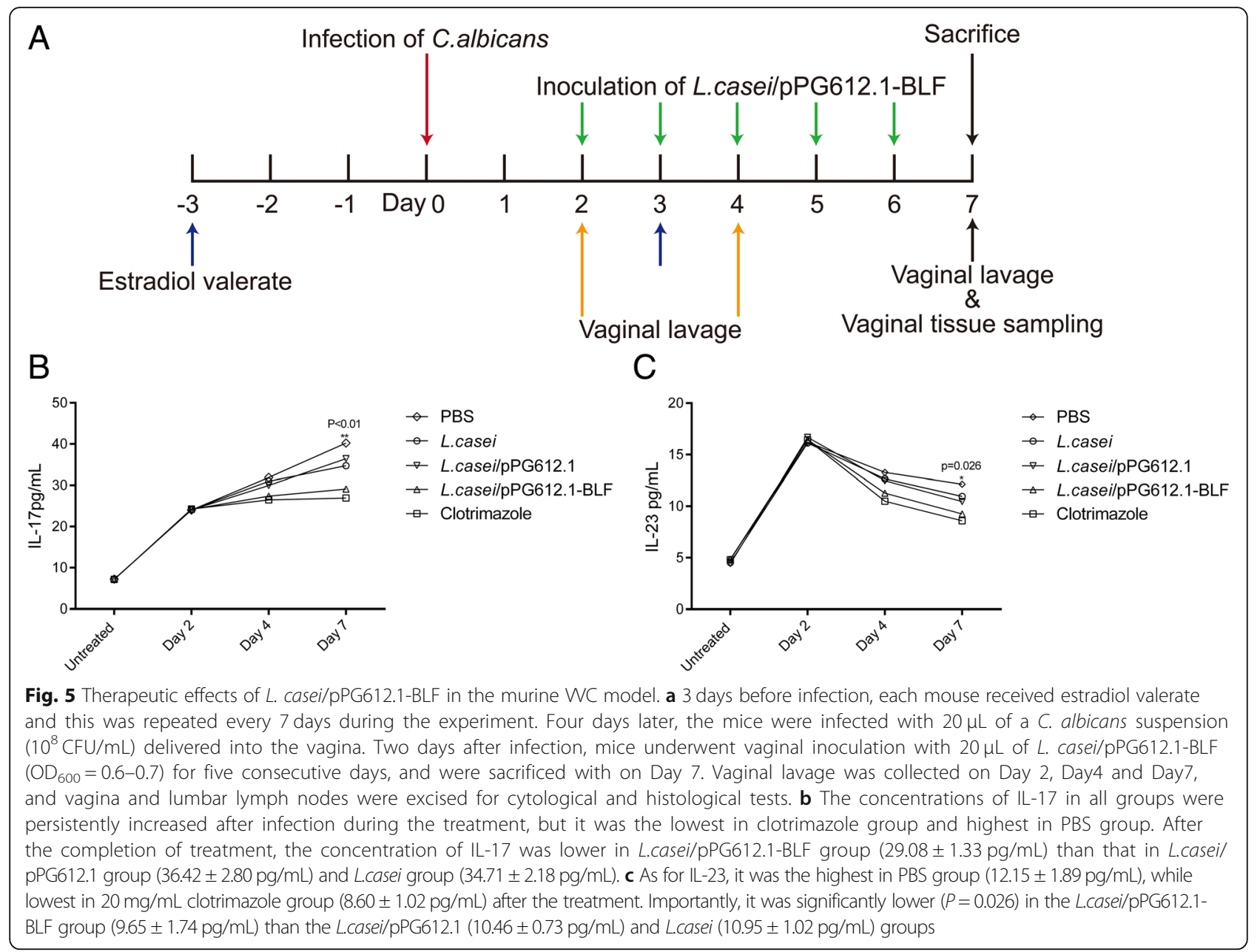

pseudohyphae and blastoconidia; however, their quantity varied in different groups. Specifically, after treatment with L. casei/pPG612.1-BLF or $20 \mathrm{mg} / \mathrm{mL}$ clotrimazole, a lot less pseudohyphae and blastoconidia adhering to the cornified epithelial layer were observed than in groups that received L. casei/pPG612.1, L. casei, or PBS, in agreement with the Vaginal lavage CFU data (Fig. 6c). Moreover, in samples from the L. casei/pPG612.1 and L. casei groups, fewer pseudohyphae and blastoconidia were seen in the vaginal cavity

Table 2 Infection burdens of groups receiving different treatments post-infection

\begin{tabular}{lll}
\hline Treatment & \multicolumn{2}{l}{ Infection burden of WC $\left(\log _{10}\right.$ CFU) } \\
\cline { 2 - 3 } & \multicolumn{1}{l}{ Before treatment } & After treatment \\
\hline PBS & $4.76 \pm 0.341$ & $3.738 \pm 0.231$ \\
Clotrimazole & $4.766 \pm 0.284$ & $0.492 \pm 0.170^{\mathrm{a}^{*}}$ \\
L.casei/pPG612.1-BLF & $4.76 \pm 0.310$ & $1.710 \pm 0.390^{\mathrm{b}^{*}}$ \\
L.casei/pPG612.1 & $4.782 \pm 0.279$ & $3.170 \pm 0.252^{\mathrm{c}}$ \\
L.casei & $4.746 \pm 0.333$ & $2.936 \pm 0.259$ \\
\hline
\end{tabular}

$\mathrm{a}^{*} P<0.01$ in comparison with L.casei/pPG612.1-BLF

$\mathrm{b}^{*} P<0.01$ in comparison with L.casei/pPG612.1, L.casei and PBS

${ }^{c} p>0.05$ in comparison with L.casei than in samples from the PBS group. These observations were in agreement with the CFU data, indicating the effectiveness of L. casei/pPG612.1-BLF or $20 \mathrm{mg} / \mathrm{mL}$ clotrimazole in treating VVC in a murine model.

\section{Discussion}

The yeast form of C. albicans is a commensal organism that dwells in the lower genital tract of a healthy female; however, the fungus undergoes a pathogenic transformation when the balance between the pathogen and the host's immune system is perturbed. During this transformation, a rapid alteration of gene expression occurs such as SAP, ECE1 and WOR1 gene [34-36], in response to various environmental stimuli.

The defense of vaginal tissues against the invasion of Candida species depends on both innate and adaptive immunity [37, 38], and comprises secreted cytokines, antibodies, AMPs, as well as probiotics - Lactobacillus species. All these factors constitute the front-line defense barrier against Candida invasion, disturbing the fungal growth, depriving the fungus of nutrients, or regulating the immune response. The maintenance of health in the 


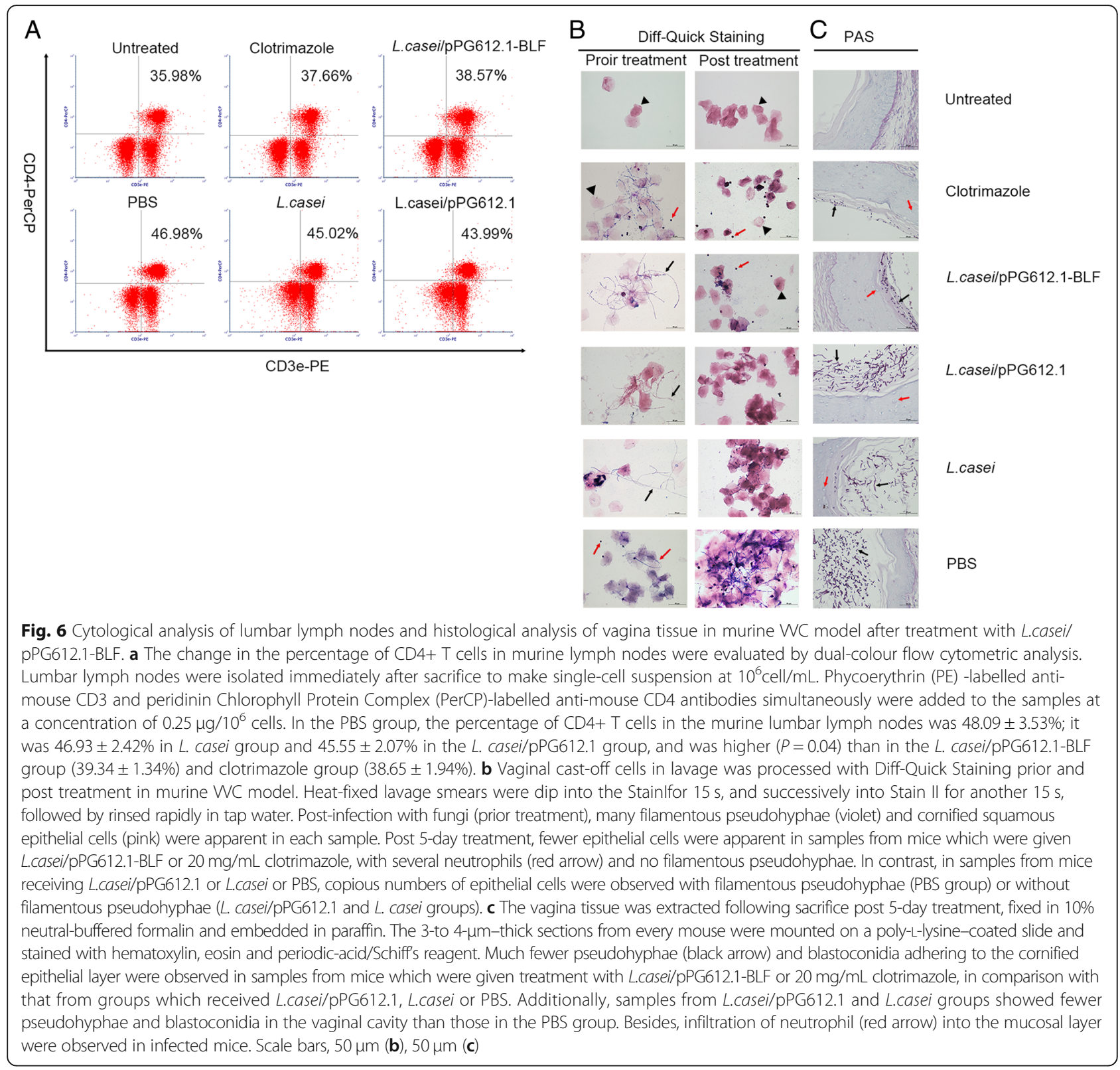

female vagina is partly attributed to the Lactobacillus species. Lactobacilli are dominant probiotic microorganisms; they produce lactic acid and other substances, contributing to the maintenance of a low $\mathrm{pH}$ in the vagina, thus preventing the overgrowth of pathogens, especially those causing bacterial vaginosis (BV), gonorrhea, and VVC. Therefore, preservation of the vaginal microbiome and reinforcement of the immunological microenvironment are feasible approaches to protection against infection with Candida sp. In the current study, we constructed a L. casei/pPG612.1-BLF strain that secreted an AMP, BLF, and tested its efficacy in the defense against and clearing of $C$. albicans in a murine model of VVC.
Human-derived lactoferrin (hLF) is already produced in $L$. casei and was shown to exert antibacterial activity in the murine gastrointestinal tract [39]. The antifungal activity of lactoferrin (human-derived and bovine-derived) stems from its ability to sequester iron, effectively starving Candida species for iron, and leading to membrane damage and leakage via iron-independent ways [23]. The plasmid pPG612.1, a mature plasmid secretion vector for Lactobacillus species, contains the ssUsp secretion signal system, and has already been successfully used for heterologous protein production in $L$. casei $[40,41]$. In the two-layer agar dish assay in the current study, BLF that was constitutively produced by $L$. casei diffused into the SDA layer, killing $C$. albicans cells and suppressing the 
growth of survivors. Despite not being 100\% effective, the same antifungal effect was also observed in the mouse model, and the fungal infection burden during VVC was apparently lower in mice that have been prophylactically inoculated with $L$. casei/pPG612.1-BLF before fungal infection than in mice inoculated with the non-BLF-secreting strains. The exogenous BLF was secreted by L. casei/ pPG612.1-BLF into the extracellular environment, participating in the defense against the invasion of $C$. albicans. In contrast, the non-BLF-secreting $L$. casei strains were not effective in defending the vaginal mucosa against $C$. albicans. Moreover, the combined results of the histological analysis of vaginal tissues, changes in the infection burdens (judged by the vaginal lavage analysis), and cytological analysis of the lumbar lymph nodes all revealed the pronounced ability of $L$. casei/pPG612.1-BLF to clear the C. albicans cells in the murine model of VVC.

The immunity mediated by $\mathrm{T}$ helper 1 (Th1) and $\mathrm{T}$ helper 17 (Th17) cells, the subsets of CD4+ T cells, is considered to be the main host defense mechanism during the clearance of $C$. albicans colonizing the vagina. These cells secrete diverse cytokines, e.g., IL-17 and IL-22, engaging in the host-pathogen interactions [42]. The protective role of IL-17, which is mainly secreted by $\mathrm{T}$ cells after activation by IL-23, is well recognized. The Th17/IL-17 pathway is involved in the secretion of AMPs and proinflammatory cytokines, as well as neutrophil recruitment [30]. Particularly, the IL-17 and IL-23 dynamics are different during VVC, with increased IL-17 levels and reduced IL-23 levels after an infection, and the IL-17 levels are positively correlated with the VVC infection burden [43]. This was also observed in the current study, with the IL-17 levels lower in the L. casei/ pPG612.1-BLF group than in L. casei/pPG612.1, L. casei and PBS groups. Lactobacillus casei/pPG612.1-BLF worked synergistically with the host immune system to defend the host against $C$. albicans invasion or clear the colonizing $C$. albicans cells, resulting in lower pathogen counts in the vagina and lightening the immunity activity; his was verified by the reduced IL-17 and IL-23 levels in the vaginal lavage and the percentage of $\mathrm{CD} 4+\mathrm{T}$ cells in the lumbar lymph nodes. Two days post-infection, a massive influx of neutrophils, the effector cells like macrophage and neutrophil of Th17 lineage through IL-17, infiltrated the vaginal cavity to mount a protective response against candidiasis [44]. After the $L$. casei/pPG612.1-BLF treatment, the amount of vaginal discharge, including neutrophils and cast-off cornified squamous epithelial cells, was reduced, indicating remission of the VVC.

\section{Conclusion}

Overall, as a prophylactic agent, $L$. casei/pPG612.1-BLF acted as an enhancer, improving the immunity of vaginal mucosa against the intrusion of $C$. albicans. Furthermore, the strain efficiently reduced the fungal burden in VVC after a 5-d treatment, although the therapeutic effect was inferior to $20 \mathrm{mg} / \mathrm{mL}$ clotrimazole. This might be improved by optimizing the dosage of the L. casei/pPG612.1-BLF or the therapeutic schedule. Although additional pathogenic Candida species and non-Candida species should be tested in further studies before making definitive conclusions, considering the unparalleled advantages of the $L$. casei strain, i.e., production of a natural AMP and its probiotic nature, the L. casei/pPG612.1-BLF might be a promising agent for treating VVC in clinical practice.

\section{Methods}

\section{Bacteria and culture medium}

Lactobacillus casei ATCC 393 (American Type Culture Collection, Manassas, Vaginia, USA) was cultured anaerobically in the Mann Rogosa Sharpe (MRS) broth (Biosharp, Hefei, China) at $37^{\circ} \mathrm{C}$ without shaking. Transformed L. casei cells were plated on the MRS agar containing $10 \mu \mathrm{g} / \mathrm{mL}$ chloromycetin $(\mathrm{Cm})$ and cultured in a sealed container at $37^{\circ} \mathrm{C}$. For protein production, $L$. casei was cultured in MRS containing 2\% $(w / v)$ xylose instead of sucrose. Escherichia coli DH5a CCTCC AB 2012883 (China Center for Type Culture Collection, Wuhan, China) was grown in LB (Biosharp, Hefei, China) medium at $37^{\circ} \mathrm{C}$ with $100 \mu \mathrm{g} / \mathrm{mL}$ ampicillin, when harboring the plasmid pUC57 (Sangon Biotech Shanghai Co., Shanghai, China), or with $30 \mu \mathrm{g} / \mathrm{mL}$ $\mathrm{Cm}$, when harboring pPG612.1 (see below). C. albicans ATCC 10231 (American Type Culture Collection) was grown in Sabouraud dextrose broth (SDB; Biosharp) at 37 ${ }^{\circ} \mathrm{C}$ with shaking at $180 \mathrm{rpm}$.

\section{Expression plasmid construction}

The pPG612.1 plasmid (BioVector NTCC Inc., Beijing, China) is an expression vector derived from the lactococcal plasmid pWV01, with the ability to replicate in $E$. coli and Lactobacillus sp. [41]. was purchased from BioVector NTCC Inc., Beijing, China. BLF gene fragment (NP_851341.1) with BamHI site at the 5 '-terminus and XhoI site at the 3 '-terminus was synthesized (Synbio Technologies, Suzhou, China) and cloned into the plasmid pUC57, resulting in pUC57-BLF. Plasmid pUC57-BLF was amplified in E. coli $\mathrm{DH} 5 \alpha$ and purified using the E.Z.N.A plasmid mini kit (Omega Bio-tek, Inc., Norcross, GA, USA). The BLF fragment was retrieved from the pUC57-BLF using BamHI and XhoI enzymes (New England Biolabs Inc., Ipswich, MA, USA) and ligated into the corresponding sites of pPG612.1, generating the plasmid pPG612.1-BLF. The ligation reaction mix was used to transform $E$. coli DH $5 \alpha$ and the resulting transformants were confirmed by PCR amplification and sequencing (Table 3).

Plasmid pPG612.1-BLF was electroporated into $L$. casei according to a standard protocol [45]. Briefly, $1 \mu \mathrm{g}$ of pPG612.1-BLF was added to $200 \mu \mathrm{L}$ of $L$. case $i$ 
Table 3 Bacterial strains, plasmids, and primers used in the current study

\begin{tabular}{|c|c|c|}
\hline Material & Description & $\begin{array}{l}\text { Reference or } \\
\text { source }\end{array}$ \\
\hline \multicolumn{3}{|l|}{ Bacteria } \\
\hline L. casei & Plasmid free & ATCC393 \\
\hline E. coli DH5a & Transformation host & $\begin{array}{l}\text { CCTCC AB } \\
2012883\end{array}$ \\
\hline L. casei/pPG6121.-BLF & Secreted BLF producer & This work \\
\hline L. casei/pPG6121 & Transformation host & This work \\
\hline \multicolumn{3}{|l|}{ Plasmid } \\
\hline pUC57 & Ampr , ori & $\begin{array}{l}\text { Sangon } \\
\text { (China) }\end{array}$ \\
\hline pPG612.1 & $\mathrm{Amp}^{r}, \mathrm{Cm}^{r}$, ori & Li et al. \\
\hline pPG612.1-BLF & $\mathrm{Amp}^{r}, \mathrm{Cm}^{r}$, ori & This work \\
\hline \multicolumn{3}{|l|}{ Primers } \\
\hline BamHI-F & TGGATCTTGCTTTGAAGGGT & This work \\
\hline BamHI-R & TTTCGTCCCATAGATCTCTGC & This work \\
\hline Xhol-F & ACACGTGAAACAGGTGCTGCT & This work \\
\hline Xhol-R & TTCGTCCAACCAAACCGACT & This work \\
\hline
\end{tabular}

ATCC American Type Culture Collection, CCTCC China Center for Type Culture Collection

(OD600 = 0.6), gently mixed, and kept on ice for $10 \mathrm{~min}$. The mix was transferred into an ice-cold electroporation cuvette with a 2-mm electrode gap, and subjected to a single electric pulse $(1.5 \mathrm{kV}, 25 \mu \mathrm{F}$, and $400 \Omega$.) using a Bio-Rad GenePulser (Bio-Rad Laboratories, Inc., Berkeley, CA, USA). The mix was diluted in $1 \mathrm{~mL}$ of fresh MRS broth and incubated anaerobically at $37^{\circ} \mathrm{C}$ for $1 \mathrm{~h}$ before spreading on MRS agar containing $10 \mu \mathrm{g} / \mathrm{mL} \mathrm{Cm}$. Plasmid pPG612.1-BLF was isolated from the L. casei/pPG612.1BLF strain using the E.Z.N.A plasmid mini kit and were identified by PCR and sequencing via ABI PRISM 3130 sequencer (Applied Biosystems, Foster City, CA, USA).

\section{Protein expression and Western blotting}

The strain $L$. casei/pPG612.1-BLF was cultivated in $200 \mathrm{~mL}$ of MRS broth supplemented with $2 \%$ xylose. An overnight culture was centrifuged at $8000 \times g$ for $3 \mathrm{~min}$, and the pellet was washed twice in PBS prior to resuspending in the lysis buffer $(50 \mathrm{mM}$ Tris- $\mathrm{HCl}, \mathrm{pH} 8.0,10 \%$ glycerol, $0.1 \%$ Triton-X-100, $100 \mu \mathrm{g} / \mathrm{mL}$ lysozyme, and $1 \times$ proteinase inhibitor cocktail). Following sonication (21\% output for 3-s pulse and 4-s rest, for $12 \mathrm{~min}$ ) in an SCIENTZ-IID apparatus (Scientz, Zhejiang, China), the sample was centrifuged at $10,000 \times g$ for $50 \mathrm{~min}$, and the supernatant was analyzed by western blotting. In addition, protein from the supernatant of the overnight culture was precipitated using $10 \%$ trichloroacetic acid, and resuspended in pure water, before analysis by western blotting.

The proteins were transferring onto a PVDF membrane, and the membrane was blocked in a blocking solution (P0252, Beyotime, Shanghai, China) for $1 \mathrm{~h}$ at $25^{\circ} \mathrm{C}$. The blots were washed six times in Tris-buffered saline with $0.05 \%$ Tween-20 for $30 \mathrm{~min}$ and between all subsequent steps for $5 \mathrm{~min}$. The blots were incubated with monoclonal mouse anti-BLF primary antibodies at the ratio of 1:1000 (ab10110, Abcam, Cambridge, UK) overnight at $4{ }^{\circ} \mathrm{C}$, and then with a horseradish peroxidase (HRP)-conjugated goat anti-mouse IgG (A0216, Beyotime). Finally, the blots were incubated with the chemiluminescent HRP substrate (ECL, Millipore, Billerica, Massachusetts, USA) and the immunolabeled bands were visualized according to the manufacturer's instructions.

\section{Fungicidal activity of $L$. casei/pPG612.1-BLF in vitro}

To evaluate the fungicidal effect of $L$. casei/pPG612.1-BLF, a two-layer agar dish assay was developed, that provided a commensal-like environment for $L$. casei and C. albicans, allowing a direct exposure of C. albicans to L. casei secretions. Sterile MRS agar and Sabouraud dextrose agar (SDA), both containing $1.5 \%$ low-melting agarose, were kept in a water bath at $37^{\circ} \mathrm{C}$. Before the experiment, $20 \mu \mathrm{L}$ of $L$. casei/pPG612.1-BLF (OD600 = 0.6) was added to $200 \mathrm{~mL}$ of MRS medium and mixed gently to avoid bubbles, in the water bath set at $37^{\circ} \mathrm{C}$. Before cooling down, $20 \mathrm{~mL}$ of the mix was poured onto a $60-\mathrm{mm}$ diameter culture dish and allowed to solidify. For a two-layer agar dish, $10 \mathrm{~mL}$ of SDA was poured on top of the MRS agar, and then allowed to solidify. Following that, $100 \mu \mathrm{L}$ of C. albicans suspension containing ca. 100 cells was placed on the surface of the two-layer agar dish, i.e., the SDA surface. Two-layer agar dishes containing L. casei/ pPG612.1, L. casei, or no L. casei were negative controls; one-layer SDA dishes (without MRS) containing C. albicans alone were blank controls. All dishes were incubated in an inverted position at $37^{\circ} \mathrm{C}$ for $48 \mathrm{~h}$, and their photographs were taken every $12 \mathrm{~h}$. The fungicidal activity of $L$. casei/pPG612.1 was assessed based on the number and average size of $C$. albicans colonies in each group. The experiment was repeated on two independent occasions with triplicate in each group.

\section{Experimental animals and compliance with ethical standards}

A total of 150 healthy female Balb/c (H-2d) mice (68-week-old, 16-18 g) were obtained from Dossy Experimental Animal Ltd. (Chengdu, China) used in the current study. Five mice were housed per one cage, and the animals were supplied with food and water ad libitum. The care, maintenance, and handling of the animals followed the requirements of the NIH guidelines for experiments with animals [46]. The animal experiment was approved by the Ethics Committee of West China Second Hospital of Sichuan University. All animal experiments were performed in duplicate. 
Colonization of murine vagina by L. casei/pPG612.1-BLF The strain $L$. casei/pPG612.1-BLF grown in $1 \mathrm{~mL}$ MRS broth containing $2 \%(w / v)$ xylose was harvested at $\mathrm{OD}_{600}=$ 0.6-0.7 and adjusted to an approximate concentration of $5 \times 10^{7}-1 \times 10^{8}$ cells $/ \mathrm{mL}$, washed three times with $1 \mathrm{~mL}$ sterile PBS, and resuspended in $1 \mathrm{~mL}$ fresh PBS. One hundred microliter of the suspension was diluted in PBS at the ratio of $1: 10$ and $1: 100$. Then, $20 \mu \mathrm{L}$ of undiluted $L$. casei/ pPG612.1-BLF suspension and of the two dilutions were inoculated into the murine vaginal cavity (5 mice per group) with a pipette at the same time of day for seven consecutive days, under the inhalation anesthesia with isoflurane (Adamas Reagent, Ltd. Shanghai,China) in a respiratory chamber with the flow rate of oxygen at $2 \mathrm{~L} / \mathrm{min}$ [47]. The mice were sacrificed by cervical dislocation $2 \mathrm{~d}$ after the 7th inoculation; each murine vagina was washed gently with $150 \mu \mathrm{L}$ of sterile PBS by repeated aspiration, 10 times. To verify the colonization of $L$. casei/pPG612.1-BLF, $100 \mu \mathrm{L}$ of the lavage was plated on MRS agar; $2 \mu \mathrm{L}$ was also used as a template in a PCR reaction to amplify the plasmid pPG612.1-BLF, using the primers mentioned above. The vaginal tissues were fixed in $4 \%$ paraformaldehyde (Biosharp) and embedded in paraffin prior to immunohistochemical analysis with anti-BLF primary antibodies.

\section{Prophylactic usage of $L$. casei/pPG612.1-BLF against murine VVC}

As specified elsewhere [48], 3 days before inoculation of L. casei/pPG612.1-BLF, each mouse received subcutaneous injection of $100 \mu \mathrm{g}$ of estradiol valerate (Aladdin Industrial Co., Shanghai, China) in $100 \mu \mathrm{L}$ of sesame oil (Bellancom Chemistry Co., Beijing, China); this was repeated every 7 days during the experiment.

Following the application of the L. casei/pPG612.1-BLF into the murine vagina, the animals were infected with $20 \mu \mathrm{L}$ of a C. albicans suspension delivered into the vaginal cavity. Briefly, $C$. albicans cells grown in SDB were harvested at $\mathrm{OD}_{600}=0.5-0.6$, washed three times with sterile $\mathrm{PBS}$, and resuspended in PBS at $10^{8} \mathrm{CFU} / \mathrm{mL}$. Mice already harboring the $L$. casei/pPG612.1-BLF were infected with $20 \mu \mathrm{L}$ of $C$. albicans suspension into the vaginal cavity (10 mice) under inhalation anesthesia as described above and kept upside-down for $5 \mathrm{~min}$. The same amounts of $\mathrm{L}$. casei/pPG612.1 and L. casei were used as negative controls; PBS was used as a blank control (10 mice per group). Two days after the infection, all mice were sacrificed and their vaginas were washed, as described above. Immediately after cervical dislocation, the vaginal tissues and lumbar lymph nodes were excised, and fixed in $4 \%$ paraformaldehyde. To assess the C. albicans infection burdens in each mouse, $10 \mu \mathrm{L}$ of the lavage was diluted in $190 \mu \mathrm{L}$ of PBS, spread on SDA, and incubated at $37^{\circ} \mathrm{C}$ for $48 \mathrm{~h}$. The remaining vaginal lavage was centrifuged and stored at $-70{ }^{\circ} \mathrm{C}$ until analysis by an enzyme-linked immunosorbent assay (ELISA; see below).

\section{Therapeutic usage of the L. casei/pPG612.1-BLF in a murine model of VVC}

Three days after subcutaneous of estradiol valerate, the mice (10 mice per group) were infected with $20 \mu \mathrm{L}$ of a C. albicans suspension $\left(10^{8} \mathrm{CFU} / \mathrm{mL}\right)$ delivered into the vagina, as described above. To assess the infection burden, 2 days after the infection, the murine vagina was washed with $150 \mu \mathrm{L}$ of PBS; from that day on, the mice underwent vaginal inoculation with $20 \mu \mathrm{L}$ of $L$. casei/ pPG612.1-BLF $\left(\mathrm{OD}_{600}=0.6-0.7\right)$ for five consecutive days [49]. The groups given $L$. casei/pPG612.1 or L. casei were negative controls; PBS was a blank control; and $20 \mathrm{mg} / \mathrm{mL}$ of clotrimazole (Q.d.) (Tokyo Chemical Industry Co., Tokyo, Japan) was a positive control. On day 3 of the treatment, each mouse vagina was washed as described above under inhalation anesthesia with isoflurane (Adamas Reagent, Ltd). Upon sacrifice on day 5 of treatment, the murine vagina was washed with $150 \mu \mathrm{L}$ of PBS, and the vaginal tissue was excised and fixed in $4 \%$ paraformaldehyde. The lumbar lymph nodes were excised and immediately prepared for dual-color flow cytometry analysis (see below). All vaginal lavage samples were processed in the same way; $10 \mu \mathrm{L}$ of the lavage was spread on SDA and C. albicans CFUs determined after $48 \mathrm{~h}$ incubation at $37^{\circ} \mathrm{C}$; the rest of the sample was kept at $-70^{\circ} \mathrm{C}$ before ELISA.

\section{Analysis of interleukins (ILs) and cast-off cells in the vaginal lavage}

The presence of ILs in the vaginal lavage was analyzed using an ELISA kit (SEA063Mu for IL-17, SEA384Mu for IL-23, Cloud-Clone Corp, Wuhan, China), according to the manufacturer's recommendations. Briefly, $100 \mu \mathrm{L}$ of the supernatants and reaction standards were placed in a 96-well plate pre-coated with a biotin-conjugated antibody; the solutions were discarded after an incubation at $37^{\circ} \mathrm{C}$ for $1 \mathrm{~h}$. Then, $100 \mu \mathrm{L}$ of a specific horseradish peroxidase-conjugated antibody solution was added to each well, and incubated at $37^{\circ} \mathrm{C}$ for $1 \mathrm{~h}$; the wells were then washed three times with PBS containing $1 \%$ Tween-20. Next, $90 \mu \mathrm{L}$ of a tetramethylbenzidine substrate solution was added to each well and incubated at $37^{\circ} \mathrm{C}$ for $10 \mathrm{~min}$ to allow for the color to develop. Finally, $50 \mu \mathrm{L}$ of a sulfuric acid solution was added to each well to stop the reaction; the plates were immediately placed in a Model 680 microplate reader (Bio-Rad Laboratories, Inc.), and sample absorbance was measured at $450 \mathrm{~nm}$.

The vaginal cast-off cells were visualized using the Diff-Quick stain (Biosharp). Briefly, heat-fixed lavage 
smears on glass slides were dipped in stain I for $15 \mathrm{~s}$, then in stain II for $15 \mathrm{~s}$; this was followed by a rapid rinse in tap water. The neutrophils were observed as cells with blue nucleus, pink cytoplasm, and violet granules; the cornified epithelial cells were stained pink; the fungi were stained blue. All slides were examined under a Leica DM1000 microscope (Leica Microsystems, Wetzlar, Germany).

\section{Cytological analysis of lumbar lymph nodes}

Dual-color flow cytometry was used to evaluate the relative changes in the percentage of $\mathrm{CD}^{+} \mathrm{T}$ cells in the lumbar lymph nodes after the VVC treatment with $L$. casei/pPG612.1-BLF. The lymph nodes were isolated from the posterior abdominal wall lateral to the abdominal aorta, and transferred into a clean dish containing RPMI-1640 medium (Corning Inc., New York, USA); they were then cut into smaller pieces. The suspension was filtered through a 70- $\mu \mathrm{m}$ cell strainer and the filtrate was centrifuged at $1500 \times g$ for $15 \mathrm{~min}$. The cell pellets were washed two times in sterile PBS, and suspended in PBS to obtain a single-cell suspension of $10^{6}$ cells $/ \mathrm{mL}$. Phycoerythrin (PE) -labeled anti-mouse CD3 (100,431, Biolegend, San Diego, CA, USA) and peridinin Chlorophyll Protein Complex (PerCP)-labeled anti-mouse CD4 (100,431, Biolegend) antibodies were simultaneously were added to the samples at a concentration of $0.25 \mu \mathrm{g} / 10^{6}$ cells; the mixtures were left to react on ice for $30 \mathrm{~min}$ in the dark before analysis. The flow cytometry analysis was performed using a Cytomics FC 500 instrument (Beckman Coulter, Inc., Pasadena, CA, USA), and the data were collected and analyzed using FCS Express 6 (De Novo Software, Glendale, CA, USA).

\section{Histological analysis of the vaginal tissue}

The murine vagina was entirely extracted, and then fixed in $4 \%$ paraformaldehyde $\left(48 \mathrm{~h}\right.$ at $\left.4{ }^{\circ} \mathrm{C}\right)$ after wash with fresh PBS. The tissues were then embedded in paraffin before being sectioned transversely into $3 \mu \mathrm{m}$-thick sections. The tissue sections from each mouse were placed on poly-L-lysine-coated slides and stained with hematoxylin, eosin, and periodic-acid/Schiff's reagent (PAS) [50]. The slides were observed under a Leica DM1000 microscope (Leica Microsystems, Wetzlar, Germany).

\section{Statistical analysis}

Comparison of the infection burden of VVC in different groups was analyzed using the Mann-Whitney U-test done using SPSS (version 22, IBM, Armonk, NY, USA). The other quantitative data was analyzed by one-way analysis of variance (ANOVA) in SPSS. Significance was set at a $P$-value $<0.05$ in all analysis.

\section{Abbreviations}

BLF: Bovine lactoferrin; C. albicans: Candida. Albicans; L.casei: Lactobacillus casei; MRS: Mann Rogosa Sharpe; PBS: Phosphate-buffered saline;

SDA: Sabouraud dextrose agar; WC: Vulvovaginal candidiasis

\section{Acknowledgements}

Thanks Dr. Wei for offering suggestions in statistical methods.

\section{Funding}

This work was supported by a research grant from the National Natural Science Foundation of China [grant number 81270060] in the design of the study and collection, analysis, and interpretation of data.

\section{Availability of data and materials}

The original datasets used and/or analysed during the current study are available from the corresponding author on reasonable request.

\section{Authors' contributions}

$H \mathrm{~L}$ participated in the design of the study, constructed the plasmid, conducted most of the experiments both in vitro and in vivo, and drafted this manuscript. S L and H W designed the experiment, interpreted the data, and revised the manuscript. H S participated in the construction of plasmid and data analysis. $Z \mathrm{~L}$ was involved in the construction of murine WC model, immunohistochemical analysis, Diff-Quick staining and data analysis in the experiment in vivo. All authors have approved to publish the data in this final manuscript.

\section{Ethics approval}

The care, maintenance, and handling of the animals followed the requirements of the NIH guidelines for experiments with animals. The animal experiment was approved by the Ethics Committee of West China Second Hospital of Sichuan University.

\section{Consent for publication}

Not applicable

\section{Competing interests}

The authors declare that they have no competing interests.

\section{Publisher's Note}

Springer Nature remains neutral with regard to jurisdictional claims in published maps and institutional affiliations.

Received: 29 March 2018 Accepted: 10 December 2018 Published online: 08 January 2019

\section{References}

1. Spence D. Candidiasis (vulvovaginal). BMJ Clin Evid. 2010;2010:1-39.

2. Anderson MR, Klink K, Cohrssen A. Evaluation of vaginal complaints. JAMA. 2004;291:1368-79.

3. Mitchell H. Vaginal discharge--causes, diagnosis, and treatment. BMJ. 2004:328:1306-8.

4. Khanmohamadi M, Mehbod ASA, Noraeepour M, Didehdar M. Molecular identification of candida species isolated from women with vulvovaginal candidiasis: brief report. Tehran Univ Med J TUMS Publ. 2017;75:538-42.

5. Achkar JM, Fries BC. Candida infections of the genitourinary tract. Clin Microbiol Rev. 2010;23:253-73.

6. Spampinato C, Leonardi D. Candida infections, causes, targets, and resistance mechanisms: traditional and alternative antifungal agents. Biomed Res Int. 2013;2013:204237.

7. Cassone A. Vulvovaginal Candida albicans infections: pathogenesis, immunity and vaccine prospects. BJOG Int J Obstet Gynaecol. 2015;122:785-94.

8. Mayer FL, Wilson D, Hube B. Candida albicans pathogenicity mechanisms. Virulence. 2013:4:119-28.

9. Pappas PG, Kauffman CA, Andes D, Benjamin DK, Calandra TF, Edwards JE, et al. Clinical practice guidelines for the management of candidiasis: 2009 update by the Infectious Diseases Society of America. Clin Infect Dis Off Publ Infect Dis Soc Am. 2009:48:503-35.

10. Dovnik A, Golle A, Novak D, Arko D, Takač I. Treatment of vulvovaginal candidiasis: a review of the literature. Acta Dermatovenerol Alp Pannonica Adriat. 2015;24:5-7. 
11. Prasad R, Goffeau A. Yeast ATP-binding cassette transporters conferring multidrug resistance. Annu Rev Microbiol. 2012;66:39-63.

12. Mulu A, Kassu A, Anagaw B, Moges B, Gelaw A, Alemayehu M, et al. Frequent detection of "azole" resistant Candida species among late presenting AIDS patients in Northwest Ethiopia. BMC Infect Dis. 2013;13:82

13. Ostrosky-Zeichner L, Casadevall A, Galgiani JN, Odds FC, Rex JH. An insight into the antifungal pipeline: selected new molecules and beyond. Nat Rev Drug Discov. 2010;9:719-27.

14. Castelli MV, Butassi E, Monteiro MC, Svetaz LA, Vicente F, Zacchino SA. Novel antifungal agents: a patent review (2011 - present). Expert Opin Ther Pat. 2014;24:323-38

15. Liu S, Hou Y, Chen X, Gao Y, Li H, Sun S. Combination of fluconazole with non-antifungal agents: a promising approach to cope with resistant Candida albicans infections and insight into new antifungal agent discovery. Int J Antimicrob Agents. 2014:43:395-402.

16. Yeaman MR, Yount NY. Unifying themes in host defence effector polypeptides. Nat Rev Microbiol. 2007;5:727-40.

17. Yarbrough VL, Winkle S, Herbst-Kralovetz MM. Antimicrobial peptides in the female reproductive tract: a critical component of the mucosal immune barrier with physiological and clinical implications. Hum Reprod Update. 2015;21:353-77.

18. Ganz T. Defensins: antimicrobial peptides of innate immunity. Nat Rev Immunol. 2003:3:710-20.

19. Gifford JL, Hunter HN, Vogel HJ. Lactoferricin: a lactoferrin-derived peptide with antimicrobial, antiviral, antitumor and immunological properties. Cell Mol Life Sci CMLS. 2005;62:2588-98.

20. Bruni N, Capucchio M, Biasibetti E, Pessione E, Cirrincione S, Giraudo L, et al. Antimicrobial activity of Lactoferrin-related peptides and applications in human and veterinary medicine. Molecules. 2016;21:752.

21. Huertas Méndez N, Vargas Casanova Y, Gómez Chimbi A, Hernández E, Leal Castro A, Melo Diaz J, et al. Synthetic peptides derived from bovine Lactoferricin exhibit antimicrobial activity against E. coli ATCC 11775, S. maltophilia ATCC 13636 and S. enteritidis ATCC 13076. Molecules. 2017;22:452.

22. Manzoni P, Stolfi I, Messner H, Cattani S, Laforgia N, Romeo MG, et al. Bovine Lactoferrin prevents invasive fungal infections in very low birth weight infants: a randomized controlled trial. Pediatrics. 2012;129:116-23.

23. Fernandes KE, Carter DA. The antifungal activity of Lactoferrin and its derived peptides: mechanisms of action and synergy with drugs against fungal pathogens. Front Microbiol. 2017;8. https://doi.org/10.3389/fmicb. 2017.00002.

24. Petrova MI, Lievens E, Malik S, Imholz N, Lebeer S. Lactobacillus species as biomarkers and agents that can promote various aspects of vaginal health. Front Physiol. 2015;6. https://doi.org/10.3389/fphys.2015.00081.

25. Tachedjian G, Aldunate M, Bradshaw CS, Cone RA. The role of lactic acid production by probiotic lactobacillus species in vaginal health. Res Microbiol. 2017;168:782-92.

26. Xu Y, Cui L, Tian C, Zhang G, Huo G, Tang L, et al. Immunogenicity of recombinant classic swine fever virus $C D 8+T$ lymphocyte epitope and porcine parvovirus VP2 antigen Coexpressed by lactobacillus casei in swine via Oral vaccination. - Clin Vaccine Immunol CVI. 2011;18:1979-86.

27. Salva S, Marranzino G, Villena J, Agüero G, Alvarez S. Probiotic lactobacillus strains protect against myelosuppression and immunosuppression in cyclophosphamide-treated mice. Int Immunopharmacol. 2014;22:209-21.

28. Gil NF, Martinez RCR, Gomes BC, Nomizo A, Martinis ECPD. Vaginal lactobacilli as potential probiotics against Candida spp. Braz J Microbiol. 2010;41:6-14.

29. Santos CMA, Pires MCV, Leão TL, Hernández ZP, Rodriguez ML, Martins AKS, et al. Selection of lactobacillus strains as potential probiotics for vaginitis treatment. Microbiology. 2016;162:1195-207.

30. Conti HR, Shen F, Nayyar N, Stocum E, Sun JN, Lindemann MJ, et al. Th17 cells and IL-17 receptor signaling are essential for mucosal host defense against oral candidiasis. J Exp Med. 2009;206:299-311.

31. Huppler AR, Bishu S, Gaffen SL. Mucocutaneous candidiasis: the IL-17 pathway and implications for targeted immunotherapy. Arthritis Res Ther. 2012;14:217.

32. Conti HR, Gaffen SL. IL-17-mediated immunity to the opportunistic fungal pathogen Candida albicans. J Immunol. 2015;195:780-8.

33. Taylor PR, Roy S, Leal SM, Sun Y, Howell SJ, Cobb BA, et al. Activation of neutrophils by autocrine IL-17A-IL-17RC interactions during fungal infection is regulated by IL-6, IL-23, RORyt and dectin-2. Nat Immunol. 2014;15:143-51.
34. Zhang S, Zhang T, Yan M, Ding J, Chen J. Crystal structure of the WOPRDNA complex and implications for Wor1 function in white-opaque switching of Candida albicans. Cell Res. 2014;24:1108-20.

35. Pericolini E, Gabrielli E, Amacker M, Kasper L, Roselletti E, Luciano E, et al. Secretory aspartyl proteinases cause vaginitis and can mediate vaginitis caused by Candida albicans in mice. MBio. 2015:6:e00724-15.

36. Richardson JP, Mogavero S, Moyes DL, Blagojevic M, Krüger T, Verma AH, et al. Processing of Candida albicans Ece1p is critical for Candidalysin maturation and fungal virulence. MBio. 2018;9:e02178-17.

37. Gazendam RP, van Hamme JL, Tool AT, van Houdt M, Verkuijlen PJ, Herbst $M$, et al. Two independent killing mechanisms of Candida albicans by human neutrophils: evidence from innate immunity defects. Blood. 2014; 124(4):590-7.

38. Richardson JP, Moyes DL. Adaptive immune responses to Candida albicans infection. Virulence. 2015;6:327-37.

39. Chen H-L, Lai Y-W, Chen C-S, Chu T-W, Lin W, Yen C-C, et al. Probiotic lactobacillus casei expressing human lactoferrin elevates antibacterial activity in the gastrointestinal tract. Biometals Int J role met ions biol. Biochem Med. 2010;23:543-54.

40. Yigang XU, Yijing LI. Construction of recombinant lactobacillus case efficiently surface displayed and secreted porcine parvovirus VP2 protein and comparison of the immune responses induced by oral immunization. Immunology. 2008;124:68-75.

41. Qiao X, Li G, Wang X, Li X, Liu M, Li Y. Recombinant porcine rotavirus VP4 and VP4-LTB expressed in lactobacillus casei induced mucosal and systemic antibody responses in mice. BMC Microbiol. 2009:9:249.

42. Mengesha BG, Conti HR. The Role of IL-17 in Protection against Mucosal Candida Infections. J Fungi (Basel). 2017;3(4):52.

43. Pietrella $D$, Rachini A, Pines M, Pandey N, Mosci P, Bistoni F, et al. Th17 cells and IL-17 in protective immunity to vaginal candidiasis. PLoS One. 2011:6:e22770.

44. Hernández-Santos N, Huppler AR, Peterson AC, Khader SA, McKenna KC, Gaffen SL. Th17 cells confer long-term adaptive immunity to oral mucosal Candida albicans infections. Mucosal Immunol. 2013;6:900-10.

45. Aukrust TW, Brurberg MB, Nes IF. Transformation of lactobacillus by electroporation. Methods Mol Biol Clifton NJ. 1995;47:201-8.

46. National Research Council (US) Committee for the Update of the Guide for the Care and Use of Laboratory Animals. Guide for the Care and Use of Lab Anim. 8th ed. Washington (DC): National Academies Press (US); 2011. http://www.ncbi.nlm.nih.gov/books/NBK54050/

47. Pascual L, Ruiz F, Giordano W, Barberis IL. Vaginal colonization and activity of the probiotic bacterium lactobacillus fermentum L23 in a murine model of vaginal tract infection. J Med Microbiol. 2010;59(Pt 3):360-4.

48. Yano J, Fidel PL. Protocols for vaginal inoculation and sample collection in the experimental mouse model of Candida vaginitis. J Vis Exp JoVE. 2011;58:1-7.

49. Stevens DA, Calderon L, Martinez M, Clemons KV, Wilson SJ, Selitrennikoff CP. Zeamatin, clotrimazole and nikkomycin Z in therapy of a Candida vaginitis model. J Antimicrob Chemother. 2002:50:361-4.

50. MCMANUS JFA. Histological and histochemical uses of periodic acid. Stain Technol. 1948:23:99-108.

Ready to submit your research? Choose BMC and benefit from:

- fast, convenient online submission

- thorough peer review by experienced researchers in your field

- rapid publication on acceptance

- support for research data, including large and complex data types

- gold Open Access which fosters wider collaboration and increased citations

- maximum visibility for your research: over $100 \mathrm{M}$ website views per year

At $\mathrm{BMC}$, research is always in progress.

Learn more biomedcentral.com/submission 